\title{
Detection and Identification of Microbial Contaminant in Bakery Products in Yogyakarta City, Indonesia
}

\author{
Evelyn Ferdian ${ }^{1}$, Catarina Aprilia Ariestanti ${ }^{1}$, and Tri Yahya Budiarso ${ }^{1 *}$ \\ ${ }^{1}$ Faculty of Biotechnology, Duta Wacana Christian University, Yogyakarta, Indonesia
}

\begin{abstract}
Bread has been chosen as an alternative food because of its availability. In Indonesia, consumption of breads is increased due to the change of diet pattern into packed and ready-made meals. Therefore, it is important to raise the awareness of bakery products quality. The purpose of this study was to detect and identify the microbial contaminant in bakery products in Yogyakarta City, Indonesia. Bacterial colonies from expired bakery products were isolated into pure isolate then confirmed by API Staph and Polymerase Chain Reaction (PCR) method. The results showed there were five kinds of gram-positive bacteria. Isolated bacteria identified by API were Bacillus cereus (52.8\%), Bacillus subtilis (97.7\%), Staphylococcus aureus $(97.7 \%)$, Staphylococcus epidermidis (97,9\%) and Staphylococcus saprophyticus (72,2\% and 61,8\%).
\end{abstract}

Keywords: bakery products, microbial contaminant, API Staph, PCR, mold

\section{Introduction}

Breads are considered as an important food in Western countries and recognized as starchy food together with rice, potatoes, pasta and breakfast cereals (O'Connor, 2012). It has been chosen as an alternative food because of its availability in the market, furthermore it is easy to reach by everyone. These days, bread has many variations based on its flavor and type, such as sliced bread, pizza and donut that makes bread is delighted by all ages (Edwards, 2007). Ingredients, baking process and environment are the crucial factors that affected the quality and safeness of the bakery products. The chance of contaminants to enter the product increased along with poor baking process and unhygiene environment. Contaminants might caused poisonings which lead into diseases if it is consumed (Saranraj and Geetha, 2012). Bacteria (Salmonella sp., Bacillus sp., \& Staphylococcus sp.) and mold (Rhizopus sp., \& Aspergillus sp.) are the common contaminants found in bakery products. One of the examples of the common contaminants found on bakery products is the case that was occurred in May 2013 at Ben Tre, Vietnam. Total

\footnotetext{
*Corresponding author:

Tri Yahya Budiarso,

Faculty of Biotechnology, Duta Wacana Christian University, J1. Dr. Wahidin Sudirohusodo 5-25, Yogyakarta, Indonesia, 55224

E-mail : yahya@staff.ukdw.ac.id
}

of 173 people suffered from gastroenteritis because they consumed the breads that was contaminated. Food Safety Agency (FSA) later found the microbial contaminant was Salmonella sp. (Vo et al., 2014).

Indonesia, as low and middle-income countries (LMICs), the diets pattern has changed into increasing consumption of packed and ready-made meals (Colozza and Avendano, 2019), including bakery products. There were some cases of food poisoning in Indonesia because of unstandardized quality of bread products. Yet the research about it was so limit thus, inhibited the information of its microbial contaminants toxicity. As a part of Indonesian food consumption, it is necessary to improve the quality of bread from its ingredients, environment and baking process. It is important to know the possibility of contamination during bread making. Based on that fact, this research was conducted as an initial step to give the information about the bread contaminant to prevent poisoning case because of bread consumption. Therefore, the purpose of this study was to detect and identify the microbial contaminant in bakery products.

\section{Materials and Methods Materials}

The samples were 30 pieces of bakery products from 10 types of bread that have been randomly collected from 10 places 
(market, shops and canteens) in Yogyakarta City, Indonesia. Three samples were taken from each places. The condition of samples were fresh bakery product with the time of storage about 0-2 days from production time. The samples were analyzed with 3 replication for each methodologies. Peptone water, malt extract agar (MEA), nutrient agar (NA), mannitol salt agar (MSA) and baird-parker agar (BPA), brain heart infusion agar (BHIA) and potato dextrose agar (PDA) were purchased from Millipore Corp. (Massachusetts, USA). Mannitol yolk polymyxin (MYP) agar was purchased from Hardy diagnostics (California, USA). Gram stain reagent and endospore stain reagent were purchased from Quelab Laboratories Inc. (Montreal, Canada). API Staph was purchased from bioMerieux Company (Marcy-l'Étoile, France) and 100 bp DNA Ladder was purchased from Thermo Fisher Scientific (Massachusetts, USA). All chemicals and reagents were of analytical grade.

\section{Methods}

Isolation and identification of bacteria

Thesample $(10 \mathrm{~g})$ was dissolved into $90 \mathrm{~mL}$ of $1 \%$ peptone water and incubated for $12 \mathrm{~h}$ in room temperature for the resuscitation process, then diluted into $10^{-5}, 10^{-6}$ and $10^{-7}$ solution. Each of the solution was inoculated into growth medium in petri disk. Based on the previous studies, mannitol yolk polymyxin (MYP) and baird-parker agar (BPA) were selected to be the growth medium for inoculation and incubation of the solution in $37^{\circ} \mathrm{C}$ for $24-48 \mathrm{~h}$. The steps were repeated until the pure culture obtained and selected as the collection sample. This culture then being identified by biochemistry analyses for coloring the bacteria and its endospore. Motility and confirmation analysis was done using API Staph.

Detection of nuc gene of Staphylococcus aureus isolate

Deoxyribonucleic acid (DNA) of Staphylococcus aureus was isolated using The Wizard ${ }^{\circledR}$ Genomic DNA Purification Kit and the identification was done using polymerase chain reaction (PCR, SureCycler 8800 Thermal cycler, Agilent, CA, USA) with the reference primer from Kim et al. (2001) with the fragment length of $270 \mathrm{bp}$. The amplification was done for 35 cycles with pre-denaturation at $95{ }^{\circ} \mathrm{C}$ for $2 \mathrm{~min}$, denaturation at $95^{\circ} \mathrm{C}$ for $1 \mathrm{~min}$, annealing at $58^{\circ} \mathrm{C}$ for $30 \mathrm{~s}$, extension at $72^{\circ} \mathrm{C}$ for $1 \mathrm{~min}$ and final extension at $72{ }^{\circ} \mathrm{C}$ for $5 \mathrm{~min}$.

\section{Detection of sea gene of Staphylococcus sp.}

DNA of Staphylococcus sp. was isolated using The Wizard $®$ Genomic DNA Purification Kit and the identification was done using PCR with the reference primer from Johnson et al. (1991), with the fragment length of $120 \mathrm{bp}$. The amplification was done for 35 cycles with predenaturation at $95^{\circ} \mathrm{C}$ for $3 \mathrm{~min}$, denaturation at $94{ }^{\circ} \mathrm{C}$ for $2 \mathrm{~min}$, annealing at $58{ }^{\circ} \mathrm{C}$ for $90 \mathrm{~s}$, extension at $72^{\circ} \mathrm{C}$ for $1 \mathrm{~min}$ and final extension at $72{ }^{\circ} \mathrm{C}$ for $5 \mathrm{~min}$.

Detection of hbl and nhe gene of Bacillus sp. isolate

DNA of Bacillus sp. was isolated using The Wizard® Genomic DNA Purification Kit and the identification was done using PCR with the reference method from Soleimani et al. (2018). The primer used were 3 pairs of non-hemolytic enyerotoxin (Nhe) and hemolysin $\mathrm{BL}(\mathrm{Hbl})$ toxin with different fragment length. The amplification was done for 35 cycles with pre-denaturation at $94{ }^{\circ} \mathrm{C}$ for $5 \mathrm{~min}$, denaturation at $94{ }^{\circ} \mathrm{C}$ for $1 \mathrm{~min}$, annealing at $49{ }^{\circ} \mathrm{C}$ for $1 \mathrm{~min}$ and $52{ }^{\circ} \mathrm{C}$ for 1 min, extension at $72{ }^{\circ} \mathrm{C}$ for $10 \mathrm{~min}$ and final extension at $4{ }^{\circ} \mathrm{C}$ for $30 \mathrm{~min}$.

\section{Results \\ Detection of microbial contaminant in bakery product}

In this research, the calculation of the colony was done only for predicted Staphylococcus sp. in MSA medium with three replications. The result showed that in the sample, there were Staphylococcus sp. existed in the range of $1.7 \times 10^{7}$ up to $2.2 \times 10^{7} \mathrm{CFU}$ per gram sample as shown in Table 1.

Staphylococcus sp. colony were growth in MSA medium and in this research, two kind of colonies were found. First colony in Fig. 1a shows as yellow color and grow before $24 \mathrm{~h}$ of incubation and the second 
Ferdian et al.

Table 1. The amount of bacterial colony in the sample

\begin{tabular}{cc}
\hline Sample & Colony $(\mathrm{CFU} / \mathrm{g})$ \\
1 & spreader \\
2 & $3.5 \times 10^{7}$ \\
3 & spreader \\
4 & $1.7 \times 10^{7}$ \\
5 & $2.2 \times 10^{8}$ \\
6 & spreader \\
7 & spreader \\
8 & $1.4 \times 10^{8}$ \\
9 & $3.7 \times 10^{7}$ \\
10 & $2.3 \times 10^{7}$ \\
\hline
\end{tabular}

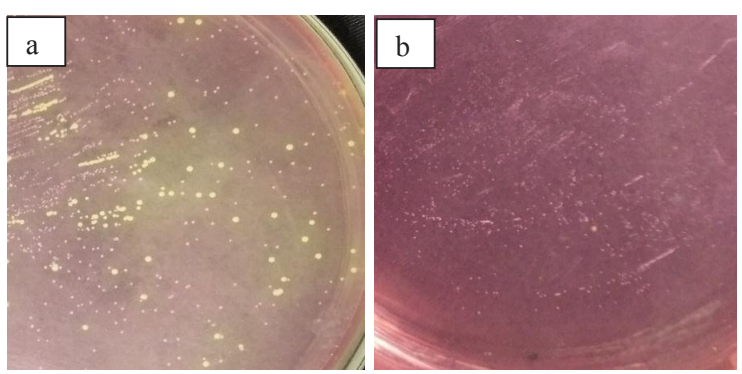

Figure 1. The growth of yellow (a) and pink (b) bacterial colony in MSA medium

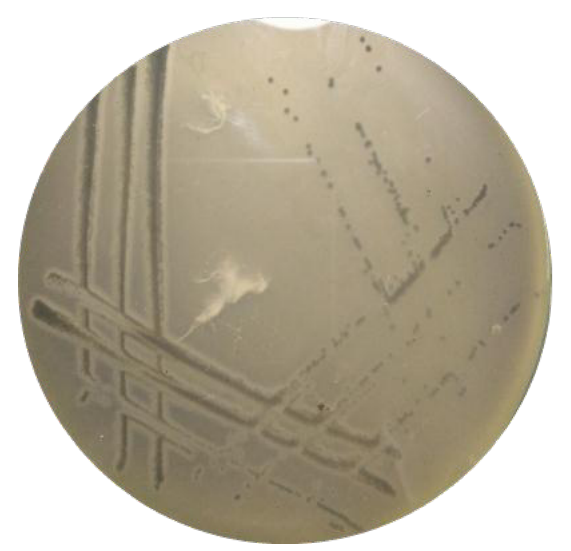

Figure 2. Bacteria colony in BPA medium

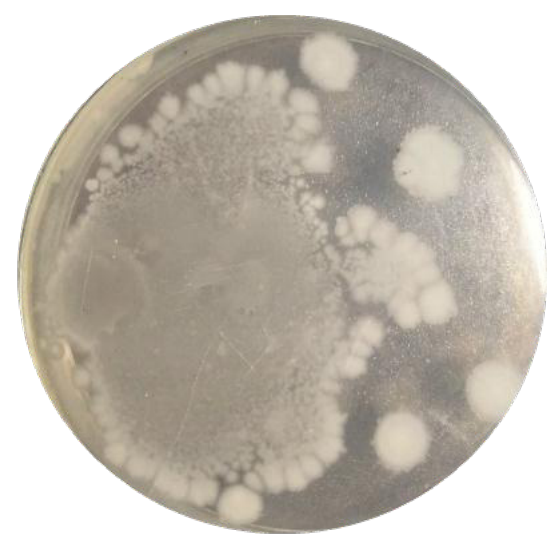

Figure 3. Bacteria colony in NA medium
Sciscitatio, Vol. 1, No. 1, Januari 2020

colony (Fig. 1b) shows to be pink color. The pink colony changed its color into yellow after $24 \mathrm{~h}$. The yellow colony was predicted as Staphylococcus aureus and another species of Staphylococcus was predicted for the second colony with pink color.

The colony that has been growth in MSA medium then re-grow in BPA medium. In this step, the result showed that the growth colony has the shiny black color with transparent zone on its surrounding (Fig. 2) and this appearance indicated as coagulase positive bacteria.

In the NA medium, the colony of bacteria, predicted as Bacillus sp., was growth as shown in Figure 3.

The predicted Bacillus sp. colony then inoculated into MYP medium. In this medium, two kind of colonies were growth. The pink color colony predicted as Bacillus cereus (Fig. 4a) and yellow colony with white edge predicted as Bacillus subtilis (Fig. 4b).

Mold contamination was also found in some of the samples after storage for 14 days inside the sterile plastic bag. The color of the mold was black (Fig. 5a) or yellow greenish (Fig. 5b) as shown in Figure 5.

\section{Identification of bacterial contaminant in the bakery product \\ Coloring the bacteria and endospore}

Two genera of bacteria that have been found was colored to see the type and shape of the bacteria cell. Under the microscope, all of the isolate bacteria showed to have purple color. The result shows that there were 16 isolates with coccus shape predicted as Staphylococcus sp. (Fig. 6a) and 16 isolates with rod shape predicted as Bacillus sp. (Fig. 6b).

Under microscope, all isolates showed green color from the Malachite green reagent as shown in Figure 7. and can be differentiate from the bacteria cell colored in red from safranin reagent.

\section{Motility analysis}

Predicted Bacillus sp. isolates were tested for its motility and the result showed that there was isolate which spread out of the initiate area in the semi solid NA medium as shown in Figure 8. 

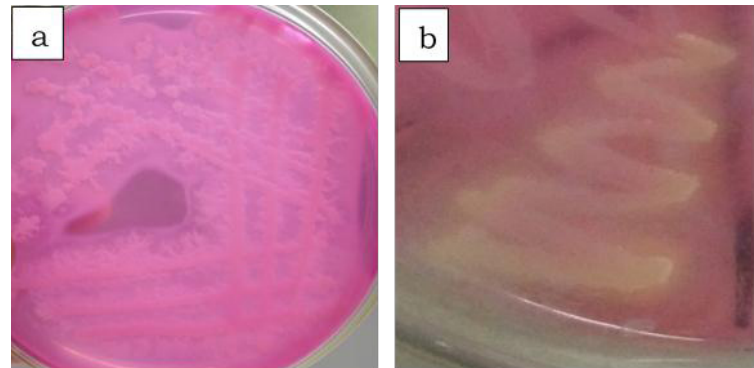

Figure 4. The pink (a) and yellow (b) colony of bacteria in MYP medium

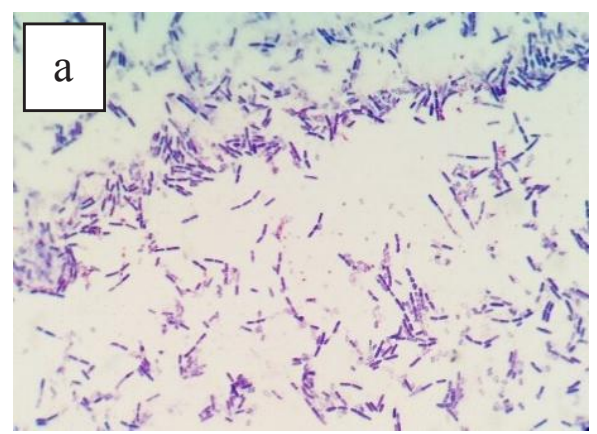

Figure 6. The coccus (a) and rod (b) shape of isolates bacteria

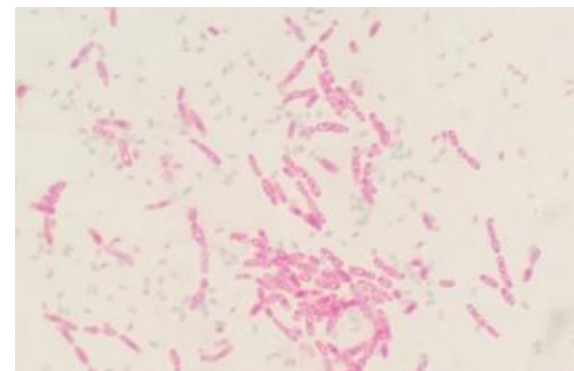

Figure 7. Endospore coloring for predicted Bacillus sp.

\section{Confirmation of predicted Staphylococcus isolate using API Staph}

Confirmation analysis was done by randomly selected six predicted Staphylococcus aureus and Staphylococcus sp. isolates to confirm the species that already found. This analysis tested the ability of isolate to ferment some kind of carbohydrate, Voges Proskauer, nitrate, alcohol dehydrogenases (ADH) and urea. The result showed there were three different species after analyzed by APIStaph as shown in Table 2.

\section{Molecular analysis}

Figure 9. shows that no nuc gene was detected (270 bp). In other hand, sea gene was detected $(120 \mathrm{bp})$ in the predicted S. aureus

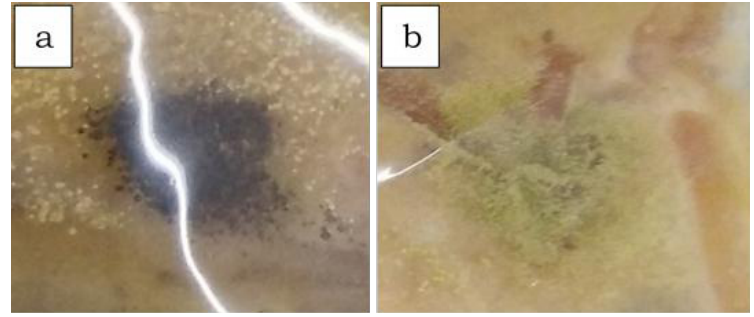

Figure 5. The black (a) and yellow greenish (b) spore of mold occurred in the sample
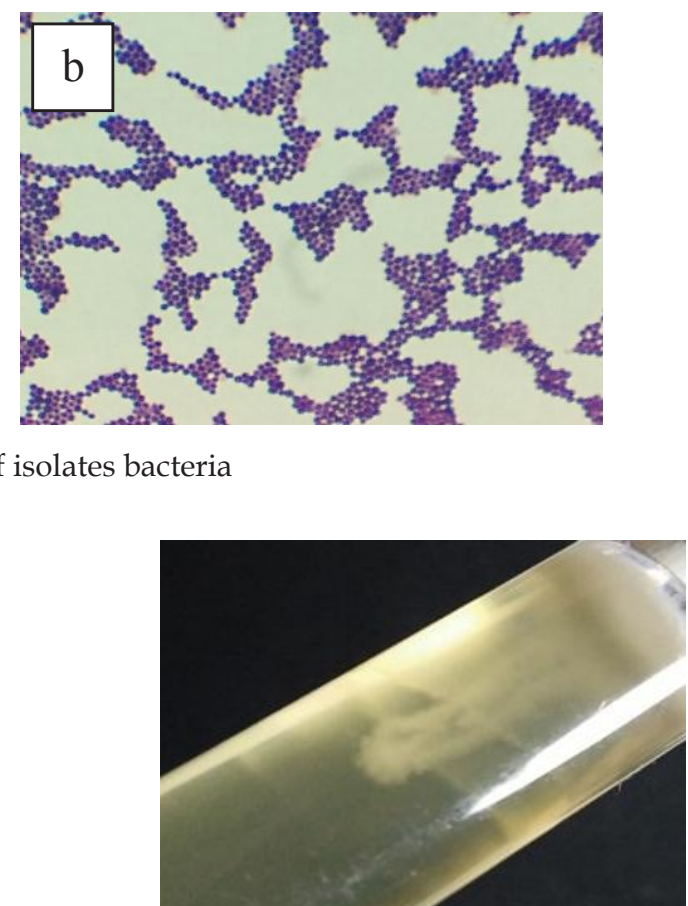

Figure 8. Motility analysis of Bacillus sp. in semi solid NA medium

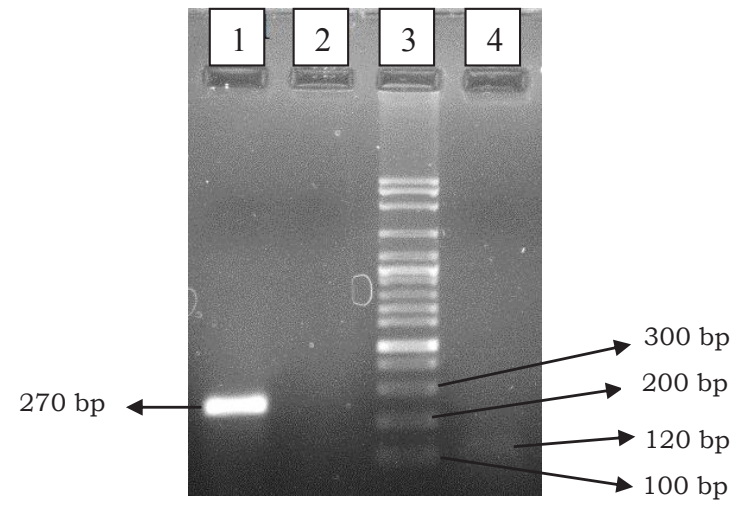

Figure 9. PCR detection of nuc and sea gene for predicted Staphylococcus aureus isolate

Note:

Line 1. Comparison isolate (nuc gene $270 \mathrm{bp}$ )

Line 2. Nuc gene isolate test

Line 3. Marker (DNA 100 bp ladder)

Line 4 . Sea gene isolate test (120 bp) 
Table 2. API Staph result of predicted Staphylococcus isolate

\begin{tabular}{ccllc}
\hline Sample & Code & \multicolumn{1}{c}{ Predicted species } & \multicolumn{1}{c}{ API Staph result } & ID (\%) \\
\hline 2 & S.2.1 & S. aureus & S. aureus & 52.8 \\
2 & S.2.2 & S. aureus & S. saprophyticus & 72.2 \\
4 & S.4.2 & S. aureus & S. aureus & 97.7 \\
6 & S.6.1 & S. epidermidis & S. epidermidis & 97.9 \\
7 & S.7.2 & S. aureus & S. saprophyticus & 61.8 \\
9 & S.9.2 & S. aureus & S. aureus & 97.7 \\
\hline
\end{tabular}

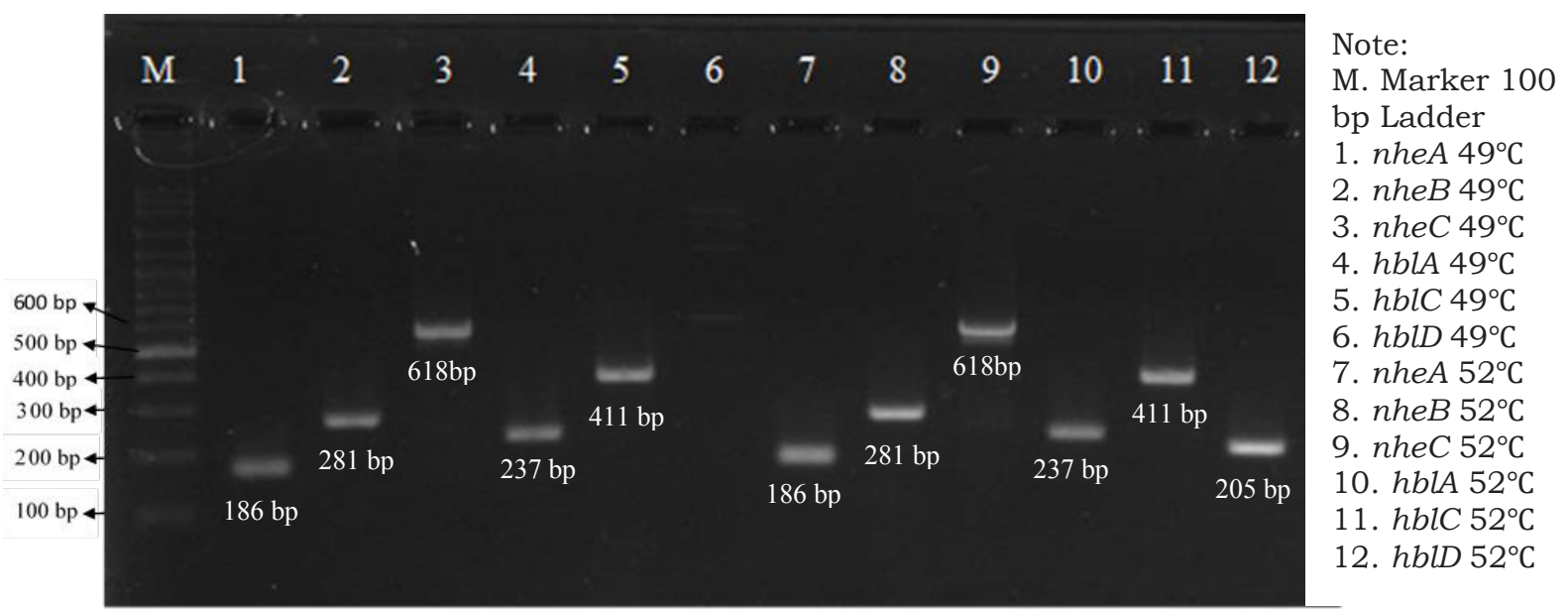

Figure 10. PCR detection of nhe and hbl gene for predicted Bacillus subtilis isolate

isolate. Predicted Bacillus subtilis isolate was found to be poisonous potency after the molecular analysis was conducted under the annealing temperature of 49 and $52{ }^{\circ} \mathrm{C}$ because all of the target gene (nheA, nheB, nhe $C, h b l A, h b l C$, and $h b l D$ ) were found in the PCR detection result (Figure 10).

\section{Discussion}

Bakery are food products that require several processes before ready to consume. Raw ingredients (eggs, water, cream, and wheat), imperfect baking and fermentation process, equipment, packaging and environment are the important factors affecting the bread quality because the contaminations are mostly happened in those factors. In this study, detection of microbial contaminant started with resuscitation to reactivate the injured microbial because of baking process. The microbial remain alive but could not grow and this is called viable but not culturable (VBNC) condition (Oliver, 2005).

Some of the bakery products used in this research from small bakery shops have the expired date on it. However, almost all the bakery products from market and school canteen did not have the expired date. The range of the bacterial colony in these samples from Table 1. could produce toxin and lead to consumer poisonous. Two genera of bacteria have been detected as the contaminant in the samples with total isolate was 32 consisted of predicted Bacillus sp. (16 isolates) and Staphylococcus sp. (16 isolates). Those bacteria survived from heat during baking process because of its peptidoglycan wall thus, predicted as gram positive bacteria. Another reason to predict the genus of bacteria was the fact that Bacillus sp. formed endospore as its defense mechanism to survive when the environment conditions were not supportive. This result was comparable with the research done by (Stenfors et al., 2008), which found out that the endospore of Bacillus cereus will be germinated in the stable environment condition and then the bacteria were reactive. The identification then to see the changing color of the predicted bacteria. The yellow colony (Fig. 1a) was predicted as Staphylococcus aureus because 
of its abilities to ferment mannitol and grow in the medium contained of $7.5 \%$ $\mathrm{NaCl}$. Second colony with pink color (Fig. 1b) was predicted as another species of Staphylococcus with the coagulase negative characteristic or Micrococcus which could not ferment mannitol but survive in $7.5 \%$ $\mathrm{NaCl}$ in the medium. These result is similar with (Kateete et al., 2010). Figure 2. was the further step to identify the appeared colony from this study. In this study, Staphylococcus aureus was predicted as the black colony with transparent zone and the other colony without transparent zone was predicted as lecithinase negative Staphylococcus aureus, another species of Staphylococcus, Bacillus spp., Preoteus spp., Enterococci and Micrococci. Those colony reduced tellurite into tellurium and the transparent zone indicated the activity of lecithinase enzyme as described from (Capita et al., 2001). The predicted Bacillus sp. shown in Figure 3 from this study were characterized as white color, contained mucous, irregular size and tend to form group of uncalculated colonies. This results were comparable with the result from (Tallent et al., 2012). The predicted Bacillus sp. colony then inoculated into MYP medium which contained of Polymyxin B to inhibit the growth of gram-negative bacteria and showed in Figure $4 \mathrm{a}$ and $4 \mathrm{~b}$. The pink color colony (Fig. 4a) indicated no mannitol was fermented. In the yellow colony (Fig. 4b), there was fermentation of mannitol and the white edge was precipitant of the egg yolk from the medium. Mold contaminant was also identified in this study by macromorphology and micromorphology. The detected mold were predicted as Aspergillus niger and Aspergillus flavus because of its characteristics were the same as described by (Silva et al., 2011), and (Gautam and Bhadauria, 2012). Bacterial contaminant was identified by coloring the bacteria and its endospore. The purple color that appeared from two founded genera was because of the peptidoglycan wall in the bacteria cell absorbed violet crystal solution and this indicated the gram-positive bacteria. Coloring the endospore was done only for predicted Bacillus sp. because of its ability to form endospore. The green color appeared from all of isolates indicated that they were Bacillus sp. Motility analysis for this predicted Bacillus sp. isolate showed that the isolate could move around the medium thus, supported the prediction that the isolate was Bacillus sp. For founded predicted Staphylococcus sp. isolates, confirmation analysis was done to confirm its species. It was found that from this study, there were three species of Staphylococcus with the highest percentage of ID $(97.9 \%)$ was found to be Staphylococcus epidermidis. Molecular analysis was done for predicted Staphylococcus aureus and Bacillus subtilis isolate because those are amongst the dangerous pathogenic bacteria. It produced enterotoxin compound that in a specific amount can be poisonous (Ahmed and Mashat, 2014).

Sea gene detected in the predicted $S$. aureus isolate indicated that this isolate produced enterotoxin $\mathrm{A}$. All of the target gene (nheA, nheB, nheC, hblA, hblC, and hblD) were found in predicted Bacillus subtilis isolate. The research from (Soleimani et al., 2018) found out that all of the target gene was produced toxin compound and commonly found in Bacillus cereus. Additional bacteria in this research was Staphylococcus sp. The total colony was more than the maximum level $\left(10^{2} \mathrm{CFU} / \mathrm{mg}\right)$ of the standard of bakery product from Badan Pengawas Obat dan Makanan Republik Indonesia/ BPOM (Badan Standarisasi Nasional, 2009). Therefore, qualitative examination is required before consumed bakery products.

\section{Conclusion}

Five kinds of gram-positive bacteria were identified in this study as the contaminant in the bakery products after their expired date. The colony of pathogenic bacteria, Staphylococcus sp., was above the maximum standard level allowed by BPOM and could cause consumer poisonous. Although this study has given the information of bakery product contaminants to consumers, further studies are necessary to understand its pathogenic mechanism. Thus, will improve food safety and raise the producers and consumers awareness of food contaminants. 


\section{References}

Ahmed, B \& Mashat, B. H. (2014). Prevalence of classical enterotoxin genes in Staphylococcus aureus isolated from food handlers in Makkah city kitchens, Asian J Science and Tech, 5(11), pp. 727-731.

Badan Standardisasi Nasional (BSN). (2009). SNI 7388, Batas Maksimum Cemaran Mikrobia dalam Pangan. Jakarta.

Capita, R., Alonso-Calleja, C., Moreno, B., \& Garcia-Fernandez, M. D. (2001). Assessment of baird-parker agar as screening test for determination of Staphylococcus aureus in poultry meat, Journal of Microbiology, 39(4), pp. 321325.

Colozza, D \& Avendano, M. (2019). Urbanisation, dietary change and traditional food practices in Indonesia: A longitudinal analysis, Social Science and Medicine. Elsevier, 233(February), pp. 103-112.

Edwards, W. P. (2007). The science of bakery products. The Royal Society of Chemistry. Cambridge, UK.

Gautam, A. K \& Bhadauria, R. (2012). Characterization of Aspergillus species associated with commercially stored triphala powder, Characterization of Aspergillus species associated with commercially stored triphala powder, 11(104), pp. 16814-16823.

Johnson, W. M., Tyler, S. D., Ewan, E. P., Ashton, F. E., Pollard, D. R., \& Rozee, K. R. (1991). Detection of genes for enterotoxins, exfoliative toxins and toxic shock syndrome toxin 1 in Staphylococcus aureus by the polymerase chain reaction, Journal of Clinical Microbiology, 29(3), pp. 426-430.

Kateete, D. P., Kimani, C. N., Katabazi, F. A., Okeng, A., Okee. M. S., Nanteza, A., Joloba, M. L., \& Najjuka. F. C. (2010). Identification of Staphylococcus aureus: DNase and Mannitol salt agar improve the efficiency of the tube coagulase test, Annals of Clinical Microbiology and Antimicrobials, 9, pp. 1-7.

Kim, B. J., Lee, K. H., Park, B. N., Kim, S. J., Bai, G. H., Kim, S. J., \& Kook, Y. H. (2001). Differentiation of mycobacterial species by PCR-restriction analysis of DNA (342 base pairs) of the RNA polymerase gene (rpoB), Journal of Clinical Microbiology, 39(6), pp. 2102-2109.

Navi, S. S., Bandyopadhyay, R., Hall, A. J., \& Bramel-Cox, P. J. (1999). A pictorial guide for the identification of mold fungi on Sorghum Grain Hall, International Crops Research Institute for Semi Arid Tropics, 1999.

O'Connor, A. (2012). An overview of the role of bread in the UK diet, Nutrition Bulletin, 37(3), pp. 193-212.

Oliver, J. D. (2005). The viable but nonculturable state in bacteria, Journal of Microbiology, 43(2), pp. 93-100.

Silva, D. M., Batista, L. R., Rezende, E. F., Fungaro, M. H. P., Sartori, D., \& Alves, E. (2011). Identification of fungi of the genus Aspergillus section nigri using polyphasic taxonomy, Brazilian Journal of Microbiology, 42(2), pp. 761-773.

Soleimani, M., Hosseini, H., Pilevar, Z., Mehdizadeh, M., \& Carlin, F. (2018). Prevalence, molecular identification and characterization of Bacillus cereus isolated from beef burgers, Journal of Food Safety, 38(1), pp. 1-8.

Stenfors, A. L. P., Fagerlund, A., \& Granum, P. E. (2008). From soil to gut: Bacillus cereus and its food poisoning toxins, FEMS Microbiology Reviews, 32(4), pp. 579-606.

Tallent, S. M., Kotewicz, K. M., Strain, E. A., \& Bennet, R. W. (2012). Efficient isolation and identification of Bacillus cereus group, Journal of AOAC International, 95(2), pp. 446-451.

Vo, T. H., Le, N. H., Cao, T. T. D., Nuorti, J. P., \& Minh, N. N. T. (2014). An outbreak of food-borne salmonellosis linked to a bread takeaway shop in Ben Tre City, Vietnam, International Journal of Infectious Diseases. International Society for Infectious Diseases, 26(2014), pp. 128-131. 